\title{
University development and the Economic Development Officer
}

\author{
David Emerson, Ec.D.
}

This paper sets out to identify elements in the relationship between universities and community economic development, and to recognize the role of the economic development officer on the integration of university activity with community economic development. Specifically, the objective is to identify the areas of common interest and between educational, government, and non-government economic development institutions using the Greater Saint John, New Brunswick context to inform and illustrate. The author concludes that Economic Development Officers (EDOs) and policy makers must incorporate university strategies and capacities into regional development, and put systems and practices in place to support economic developers in forming innovative partnerships with post-secondary institutions.

Keywords: university, community economic development, EDO, regional development

\section{Introduction}

This paper sets out to identify elements in the relationship between universities and community economic development, and to recognize the role of the economic development officer on the integration of university activity with community economic development. Specifically, the objective is to identify the areas of common interest and between educational, government, and non-government economic development institutions using the Greater Saint John, New Brunswick context to inform and illustrate.

Although universities are generally acknowledged as institutions that shape the social and technological fabric of our society, they are isolated from the networks in which the daily practice of business and economic development happens. While they are often part of our communities, they remain separate, a community within the community.

Isolation of universities from economic development doesn't serve our communities, profession, or country well. We need dialogue within our profession and our communities [especially small ones] about the ways in which we can shape local governance systems and the daily practices of local economic development to involve and integrate universities and other post secondary education institutions.

Finally, both universities and our economic development organizations will benefit from the relationships and the migration of talent this integration will bring. 
The influence of universities on local and national practices should be clear to any member of the profession who has attended the Economic Development accreditation courses in Waterloo. The long, well established, and productive relationship between the University of Waterloo and the Economic Developers Association of Canada has had far reaching benefits for Canada and beyond.

\section{University benefits to the community}

Most of us tend to think of national level strategy when considering the contribution of university activity and infrastructure to the development of our economy. This impression has been formed and reinforced by the visibility of productivity and innovation initiatives emerging from federal departments. Innovation and productivity issues, once the sole domain of the National Research Council and other 'pure' research institutions, are now entrenched within jurisdictions such as Industry Canada and ACOA (Atlantic Canada Opportunities Agency) strategies (Barker \& Doutriaux, 1995).

Most of the literature an economic developer is likely to encounter focuses on three key elements:

1. Generation of new intellectual property.

2. Commercialization of intellectual property.

3. Training of highly skilled workers. (Barker \& Doutriaux, 1995 and Gu \& Whewell, 1999)

However, universities deliver a variety of additional benefits that include but are not limited to:

\section{Recruiting and retention of youth}

University marketing and recruiting activities encourage in-migration of youth from national and international markets. Although the higher mobility displayed by educated workers and the natural tendency of youth to explore other communities and experiences as they pursue an education means that every community will experience some out migration; communities with post secondary institutions enjoy an advantage. Small communities that host larger post secondary institutions stand to benefit from in-migration that is proportionally greater compared to that experienced by larger communities. Transition to employment programming, the establishment of mentoring and personal relationships and other university (and alumni association) activities also assist in the retention of youth in the host community. In essence, communities have the opportunity to deliver a "four year sales pitch" for residency to young, educated, and relatively affluent youth. Although difficult to quantify, the long term strategic importance of this benefit, should not be underestimated. 


\section{Economic impact}

Like any large organizational venture, universities allocate capital and operating funds to buildings and infrastructure, payroll, and purchasing. Employment and business opportunities are created for affiliated commercial and personal services. Adjoining commercial property values are enhanced. Indirect impacts can include exposure of the community to external markets offered by media coverage, enhancement of local community development and quality of life, and catalyst in the development of arts and cultural industries.

\section{Infrastructure}

Universities often provide amenities that a small community is unlikely to afford on its own: athletic facilities, video-conferencing suites, reference libraries, even independent bookstore operations and high speed internet connections. Universities are often the catalyst for projects leading to capital investments in emerging technologies, with seed funding preceding the private sector. This has been demonstrated most visibly in the past with the development of the Internet, time-shared computer facilities, and testing laboratories.

\section{Collaboration \& Networking}

University campuses are a central node for academic, alumni, and personal networks that are global in scope. For business communities that foster good town-gown relationships, universities are links to external sources of data, analysis, competitive intelligence, and other industry sector information. Frequently, they create a foundation for industry sector affiliations and associations, as the University of Waterloo has done with the Economic Developers Association of Canada. In some smaller communities, the meeting and conference facilities on the university campus are a crucial social conduit for local business development.

\section{Problem Solving Capacity}

Informal problem solving through personal networks, faculty who operate consulting ventures, and even workgroup assignments and thesis research all contribute to the communities ability to resolve technical, research, and management capacity issues.

\section{Incubation}

Larger post secondary institutions are able to provide shared facilities and support services for business incubation related to the commercialization of new technology. The personal and professional networks can facilitate access to capital and generate expert advice for young entrepreneurs. 


\section{Background - Greater Saint John}

In 2000, after almost three years of operation, the Board and Management of Enterprise Saint John recognized that to maintain public and political support in requesting additional resources for community economic development, it would be advantageous to measure and communicate the effectiveness of their past and current economic development efforts. Larry Smith of Economic Essentials, a consulting firm based in Waterloo, and Dr. Emanuel Carvalho of the University of Waterloo were engaged to rank Greater Saint John's economic progress relative to selected benchmark communities in other parts of Canada.

The news about economic performance of the Greater Saint John region relative to other communities was good, but there were concerns about the ability of the community to maintain the pace of growth.

"As the rate of unemployment declines, bottlenecks in the form of skill shortages...develop, creating an impediment to effectively promoting the economic development prospects of the Greater Saint John Region (Smith \& Carvalho, 2000)".

Specifically, Smith and Carvalho and identified the out-migration of youth as a challenge for work force development, entrepreneurship development, and community vitality.

In the final report and presentation, they impressed on the audience of community leaders the importance of post secondary education institutions in attracting and retaining youth, developing the workforce, and acting as a catalyst for the creation and commercialization of intellectual property.

As a result of this report, the four mayors of Greater Saint John established an integrated growth strategy driven by a Task Force composed of volunteers (Smith \& Carvalho, 2000). A key focus of the strategy is the retention, development, and attraction of youth. The University of New Brunswick Saint John was identified as a crucial component in this initiative; the community had recognized the need to renew the link between the university and its other economic development partners.

At first glance, this appears to be a logical and pragmatic approach to the problem identified in the report and presentation, and it is. But it is also an illustration of the degree of integrated governance that communities require to remain competitive in an increasingly globalized economy. 


\section{The elements of university development, and the role of the EDO}

The majority of Economic Development Officers in Canada are most familiar with organizational development as it specifically relates to small and medium sized businesses. University development efforts address some of the same issues:

- human resources;

- research capacity;

- academic programs;

- financial support and other contributions;

- governance and community integration;

- recruiting and marketing.

\section{Human resources}

As with any other talent-based enterprise, the ability to attract and retain high quality human resources is of paramount concern. To be successful, the university must compete for skilled academic professionals and administrators. In small or remote communities, the process can be a challenge, that is all too familiar to EDO's: convincing key executive prospects to consider investing in a new role, community, and business venture outside of the perceived career 'mainstream'. Economic Developers should recognize the importance of this activity, and the assistance they can provide to university administrators by sharing services and advice.

\section{Academic and research capacity}

Product development within a university context has two main dimensions: building capacity in both academic programs and research. In the case of academic programs, activities that are responsive to the current and anticipated labour force development needs of industry and government are important to regional development. In respect to research, direction from university partners can lead to commercialization and enhanced competitiveness.

An EDO who invests time in fostering a thorough understanding of the university and its capacities, will develop the ability to assist business clients in sourcing technical, management, and training solutions by facilitating a relationship between the university and the private sector. This practice can produce gains in company and sector performance. Tactically, it can also help position the development organization as a valuable partner and add to the portfolio of services available to the client.

Like economic development organizations, universities must continually demonstrate the relevance of their activities, as these specifically apply to the needs of the host community. In 
New Brunswick, the University of New Brunswick has played a pivotal role in the social and industrial evolution of the province. Research and teaching has contributed to the development of silviculture, e-commerce, engineering, geomatics, aquaculture, and other industries in the Maritimes and beyond. Researchers and program coordinators within the university system can be a valuable source of information on relevant trends and the impact of emerging technology on industry sectors.

\section{Financial support and other contributions}

The growth and development prospects of the university, and therefore the benefits it can deliver locally is predicated on support from the community. Support comes in three forms:

- time (volunteer hours);

- talent (skills and networks);

- treasure (financial contributions).

Access to capital, which is an issue frequently encountered by business owners and the EDO, is also a constraint faced by universities. With funding from federal and provincial sources continuing to wane, the importance of annual giving, major donations, and joint venture opportunities rises. Universities are not alone in this respect, and they frequently compete within the community alongside social, arts, and other not-for-profit organizations for support. An important role for the EDO may in fact be the informal coordination of multiple local fundraising initiatives to avoid exhausting the goodwill of donors in the community and influencing the allocation of local capital to viable uses.

\section{Governance and university/community integration}

Governance enables university and other post secondary institutions to coordinate efforts with other partners. Governance is defined as being:

"about how people come together to address problems that cut across a region (Jeffrey, 2001).”

In the Greater Saint John context, the conclusions reached by the Smith/Carvalho study prompted the community to develop governance structures that linked the interests of the four communities. This points to a simple and self-evident truth: communities with flexible and responsive governance structures have a greater ability to rationally and effectively employ resources. 
As the result of recommendations contained in the 1997 Cormier Report on amalgamation and the regionalization of services in southern New Brunswick (Cormier, 1997), economic development in the municipalities of Grand Bay-Westfield, Saint John, Rothesay and Quispamsis was consolidated in the Greater Saint John Regional Economic Development Commission, Incorporated. Launched in April 1998, this new organization was appended to the province-wide Regional Economic Development Commission network; it is more commonly known under its marketing name, Enterprise Saint John.

Enterprise Saint John takes direction from a Board made up of designates from the business community (nominated by local Chambers of Commerce) and municipal government. Although appointees represent the interests of their communities, they are also expected to take a broader view of regional interests and aspirations. Staff coordinates work plans and initiatives with municipalities, federal and provincial agencies, as well as other organizations with regional outcomes in mind.

Enterprise Saint John launched a community economic development strategy premised on a balance of entrepreneurship development, existing business development, and corporate site selection initiatives. Substantial public and media support was generated through a public visioning process and extensive volunteer working groups.

Although there is no regional layer of government in Greater Saint John, the net result of this evolution has been an effective and pragmatic governance structure. As shown in Table A, each layer of government has a different set of interests when it comes to university benefits, though there is significant overlap.

Table 1. University benefits and government interests

\begin{tabular}{|l|l|l|l|l|}
\hline Issue & FEDERAL & PROVINCIAL & REGIONAL & LOCAL \\
\hline Innovation & & & & \\
\hline Training of highly skilled workers & $\square$ & $\square$ & & \\
\hline $\begin{array}{l}\text { Creation of an innovation culture or } \\
\text { capacity within the community }\end{array}$ & $\square$ & $\square$ & $\square$ & \\
\hline $\begin{array}{l}\text { Commercialization and licensing of } \\
\text { new intellectual property }\end{array}$ & $\square$ & $\square$ & $\square$ & \\
\hline $\begin{array}{l}\text { Research activity resulting in the } \\
\text { creation of new intellectual property }\end{array}$ & $\square$ & $\square$ & & \\
\hline Direct Economic Impact & & & $\square$ & \\
\hline $\begin{array}{l}\text { Capital investment in buildings and } \\
\text { infrastructure }\end{array}$ & & & & \\
\hline
\end{tabular}




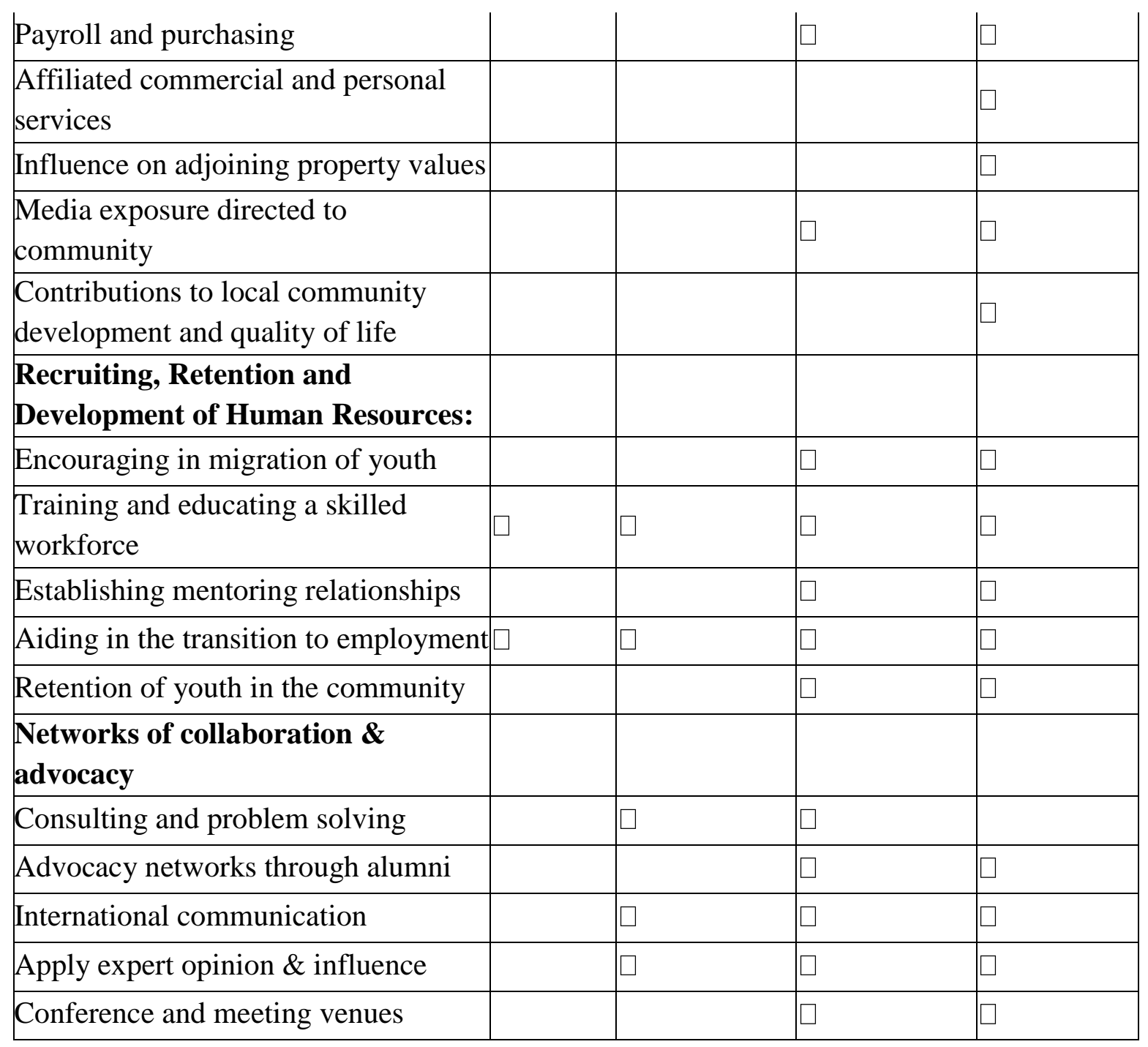

In the absence of a regional layer of government, the regional economic development agency represents the natural interface between municipal, provincial, federal, institutional and private sector interests, including those of the university.

Some university benefits, such as the direct economic impact, require relatively little coordination between the institution, economic developers, and other players. On the other hand, as Figure A demonstrates the ability of the university to integrate recruiting efforts with a regional youth retention strategy requires substantially more sophisticated interaction.

UNB Saint John's recruiting activities and the relationship with regional youth retention initiatives are an illustration of this integration. The Mayors of Grand Bay-Westfield, Saint John, Rothesay, and Quispamsis chair the Task Force on Growth. Their strategy, which is still evolving, contains approximately fourteen individual components with youth development and 
recruiting and retention as a key factor. The strategy has an internal and external communications plan representing a common foundation across all areas.

\section{Figure 1. Community benefits and integrated governance}

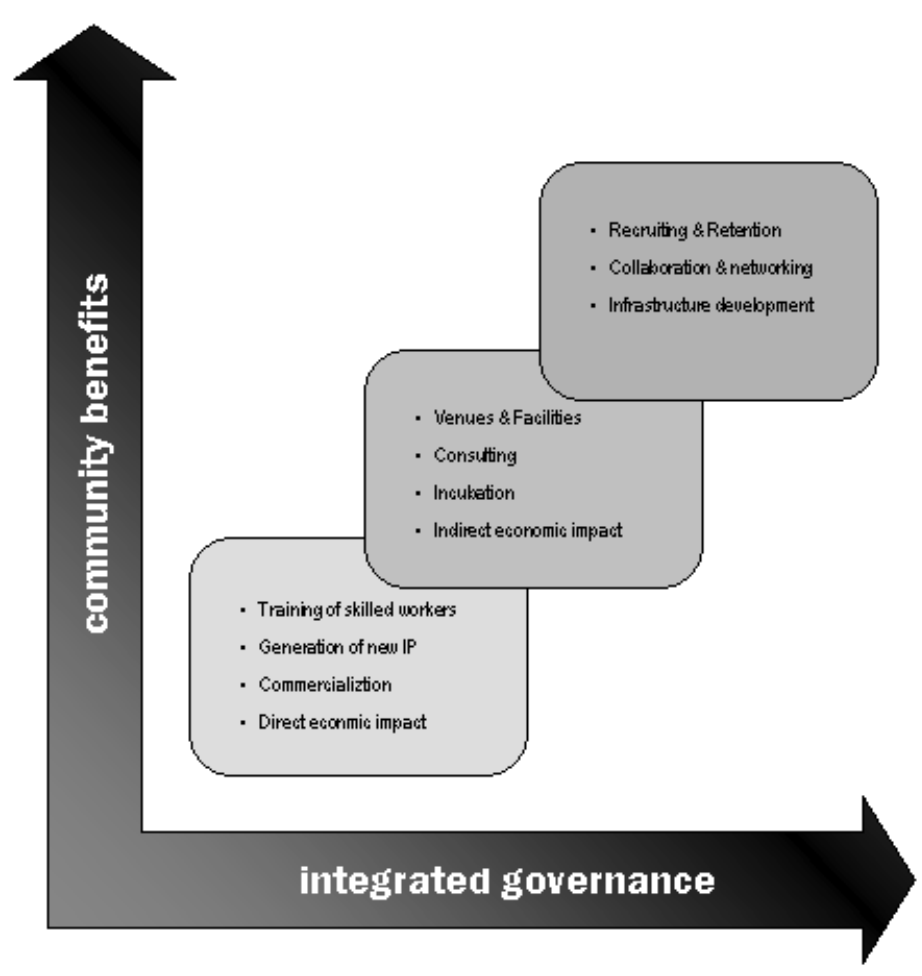

\section{Recruiting and marketing}

A substantial amount of UNB Saint John's capacity in the 1970s was devoted to helping working adults earn undergraduate degrees directly related to their occupation. In the 1980's this local adult education market diminished, however, a growing southern New Brunswick population provided enough new high school graduates to satisfy the existing capacity at the Saint John campus. By the 1990s attitudes to post secondary education changed in the province, and in the process encouraged greater participation. Successful new programs, including co-op placements, drove enrolment to new heights.

But the 1990s also introduced competition within New Brunswick. The dialogue among federal and provincial governments on the subject of post secondary education had always included questions on the desirability of having four (Mount Allison University, St Thomas University, the University of New Brunswick, and Université de Moncton) separate universities (and several 
more campuses) serving such a small population. To compound the concerns, neighbouring Nova Scotia offers an even greater array of choices while serving an overlapping geographic market.

There are non-traditional competitors in the post-secondary education sector to contend with as well. Private sector 'career colleges' like CompuCollege and ITI have invested heavily in profiling and positioning, as well as, facilities. Although they do not draw from the same pool of student candidates, they have influenced the attitudes and expectations of consumers, contributing to the complexity of the marketplace.

At the same time, the level of financial support available to universities and other post secondary institutions continues to decline. All institutions must rely more heavily on enrolment to meet budgets. This is a particularly sensitive point at UNB Saint John; the funding formula employed by the Maritime Provinces Higher Education Commission places multi-campus universities at a disadvantage, and has not benefitted the rapid growth at the Saint John campus. As a result, UNB Saint John receives about 80 per cent of what it would if it were independent. Faced with a declining pool of new graduates and escalating competition in local markets, UNB Saint John began to explore other options. Efforts to develop international markets have met with tremendous success, most notably a joint venture in China with Beijing Concord College of Sino-Canada to deliver undergraduate programs in computer science and business administration.

While external markets have continued to fuel the accelerated growth at UNB Saint John, it is important not to lose sight of the sound strategy to focus on approaches that will grow and consolidate the share of local students who remain in the community for a university education. This is a familiar refrain to the EDO evaluating export development prospects with a manufacturer: if you can't dominate your own market, how can you dominate someone else's? The argument is not entirely based on financial considerations. University administrators are interested in cultivating a campus community that offers diversity in thoughts, attitudes, and experiences. It is therefore desirable for the university to balance local, domestic (other Canadian regions) and international participation.

Heightened competition and dialogue with a youth market that is increasingly sophisticated has led universities and other educational institutions to sharpen their marketing practices. Current practices in the industry reflect the changing attitudes of consumers; they are no longer investing in academic programs alone. They are buying, at considerable cost, a university experience. Some of the elements of that product are familiar, like the campus surroundings, sports, and lectures. Other components are not as evident, for instance, the impact on public transportation, urban entertainment, off-campus housing, and spending on retail and personal services by students. 
There is a clear parallel between universities and the tourism industry; the consumer evaluates a uniform and carefully constructed package of amenities, services, and experiences. They judge the perceived merits and value of each package and select a destination. Their satisfaction is based on both objective and subjective criteria.

Successful universities and successful tourism operators share in their capacity to create a package for which the value exceeds the sum of its parts. They assess shifting market conditions, and effectively and efficiently combine private and public amenities with paid services. In each case, the reputation or brand equity established over time will contribute to the success or failure of the endeavour.

There is a fine line between marketing a community and marketing a university. Prospective students evaluate potential universities by examining the full range of available programs, amenities, and activities. Viewbooks, the promotional documents published by universities as a response to applicant inquiries, feature both community and campus attractions. The similarity of these documents to the community profiles produced by local economic developers is evidence of the potential for a convergence of interests between universities and communities. There is benefit to be gained by both partners. The university is better able to incorporate community amenities as part of the academic experience while the community gains direct access to the student market.

As pointed out in The Greater Saint John Region: Opening Doors for the Future by Smith and Carvalho, Greater Saint John lost more than 4000 young people in the preceding decade to outmigration. This has serious implications for workforce development, consumer spending, community leadership, and business formation. Although Greater Saint John demonstrated strong economic performance, the momentum of this progress is in jeopardy. Internal population growth will be insufficient; the region needs to become more successful in attracting and retaining youth.

Awareness of youth retention issues started in 1998, when Enterprise Saint John coordinated Imagine the Possibilities (Saint John, 1999). This one-day event brought together more than 250 community leaders from all walks of life and all areas of the region to articulate a shared direction for all aspects of regional development in Greater Saint John. The process identified $1500+$ new initiatives, and a framework for monitoring progress based on volunteer 'champions' in key areas, including youth. In December 1999, one year later, Imagine the Possibilities II brought participants (about 450 in total) back together to review progress, identify emerging priorities and resources, and report back to the community at large.

Although some youth from the region were involved in the Imagine the Possibilities process, it was apparent that broader consultation was necessary to gather additional information, encourage 
direction from youth, and engage volunteers. A process similar to Imagine the Possibilities was launched in May 2000, and 250 youth leaders participated in facilitated sessions outlining aspirations for Greater Saint John. Several of the services and amenities requested by youth were already available in the community, but were not recognized.

By this point, it was apparent that youth were not entirely satisfied with the community and their role in it, however, it was recognized that their continued commitment to the region would be crucial to its continued success. Greater Saint John would need to become more effective in retaining and attracting young people. In the process, a strategy was developed to:

- identify the aspects of community life most important to youth;

- address gaps in the development of local services, amenities, and activities;

- raise awareness of the comparative advantages the region offers through improved communication;

- promote networking, mentorship, and governance while involving youth in meaningful ways in the life of the community.

Marketing the community to youth involves four principle areas:

1. Research and analysis: understanding the attitudes, perceptions and preferences of youth and youth influencers.

2. Communications: coordinating contact with youth in a way that makes use of complementary messages and imagery.

3. Sense of ownership: integrate youth in the community through mentoring, leadership and networking.

4. Infrastructure: understand the needs and aspirations of youth, and develop and deliver the amenities, services, and activities that youth value.

In Greater Saint John, these developments are still unfolding as the Task Force gathers initial research and develops more refined objectives. Although it is impossible to project the impact that coordinated recruiting and retention could have on the community, a look at past enrolments can provide an indication of the potential contribution offered by university initiatives.

The Greater Saint John Region: Opening Doors for the Future estimates that more than 4,000 young people left the region in the preceding decade. In the same period (1988-1998) university enrolments, taken from UNB Saint John Registrar Barry Beckett's (1999) analysis of undergraduates consisted of:

- 6,701 new undergraduate students;

- 5,270 were from the local market (retention); and 
- 1,431 from areas beyond the region (recruits).

These enrolment figures suggest that even a small, relatively new institution can have an impact on the ability of the community to retain and attract youth. This level of performance could be enhanced by coordinating university marketing and recruiting efforts with the regional communication strategy aimed at youth.

These numbers do not measure the propensity for youth to migrate from the region upon completion of post secondary programs. Both UNB and the Associated Alumni have identified the post-graduation transition to employment as an area of particular interest. By introducing student services that support a short and comfortable move to the workforce, the institution can reinforce the perceived relevance of the university experience. Maintaining the relationship with the student introduces other dividends as well, including participation in alumni programs, groups and events.

The local EDO can be a valuable partner in the transition process. The network of local business contacts and knowledge of industry sector trends can effectively contribute in the transition to work programs. This support for transition to work initiatives can be mutually beneficial. The alumni network database is also of value to the economic development officer, allowing them to expand their circle of contacts to areas beyond the region by identifying graduates by sector, role, and location.

More research is underway in Greater Saint John to support retention initiatives. The local 'Work Ready Work Force' group is a task force composed of economic development, government, and educational partners coordinated by New Brunswick's Department of Training and Employment Development. The group is composing a survey instrument that will measure local attitudes towards education, the perceived relevance of local post secondary education programs, perceived local career development prospects, and mobility.

\section{Conclusion}

Universities deliver a variety of benefits to the host region, from the creation and commercialization of intellectual property to youth recruiting and retention initiatives. Communities that have universities enjoy a competitive advantage in economic development over those that do not. Economic developers should not take these institutions for granted, or assume that full benefits will transmit to the community without their intervention. The EDO enjoys a unique place in the life of the community and its economy, bridging personal networks and establishing the informal governance necessary to solve problems.

Support from the EDO for university development may include: 
- supporting recruiting efforts aimed at key faculty and administration positions;

- providing input on behalf of the business community to academic and research program development based on current and anticipated needs;

- facilitating the connection between local industry and university-based research and problem solving capacities;

- communicating the relevance of university research and academic programs to government and other funding sources;

- providing information to university administration to avoid conflicts among university and community fundraising efforts;

- engaging university resources as part of the region's development strategy;

- coordinating regional marketing content and practices with university recruiting and marketing initiatives to make both more effective and efficient;

- assisting in transition to employment programs by identifying local placement opportunities;

- helping universities maintain relationships and perceived relevance with graduates by involving them in regional development initiatives.

Communities with flexible and responsive governance structures have a greater ability to rationally and effectively employ resources. Some university benefits, such as local purchasing, require relatively little coordination between the institution, economic developers, and other players. On the other hand, the ability of the university to integrate recruiting efforts with a regional youth retention strategy requires substantially more sophisticated interaction. In the absence of a regional layer of government, the regional economic development agency represents the natural interface between municipal, provincial, federal, institutional and private sector interests, including those of the university. This role may be particularly important in small communities that host larger post secondary institutions, where they stand to benefit from in-migration that is proportionally greater than that of larger communities.

For the EDO and for policy makers this means incorporating university strategies and capacities into regional development, and putting the systems and practices in place to support economic developers in forming innovative partnerships with post secondary institutions.

\section{Author's biography}

David Emerson was recently appointed as Director of Advancement at the University of New Brunswick in Saint John, following ten years of experience in regional economic development in New Brunswick. He is a graduate of Ryerson University [Urban \& Regional Planning], and achieved Ec.D. accreditation in 1996. He maintains an active interest in regional development issues, particularly in the information technology and electronic commerce sectors. 


\section{Bibliography}

Atlantic Canada Opportunities Agency. 2001-2002 Estimates Part III: A Report on Plans and Priorities, Minister of Industry, Ottawa, 2001.

Barker, Margaret and Jerome Doutriaux, The University-Industry Relationship in Science and Technology, Occasional Paper No. 11, Industry Canada, Ottawa, July 1995.

Beckett, Barry, Student [Undergraduate] Profile for the Saint John Campus of the University of New Brunswick, University of New Brunswick Saint John, Saint John, 1999.

Buchanan, Peter McE., Ed., Handbook of Institutional Advancement, Council for the Advancement and Support of Education, New York, 2000.

Cormier, E.F., Commissioner, Local Government Options for the Greater Saint John Area, NB Department of Municipalities, Culture \& Housing, Fredericton, 1997.

$\mathrm{Gu}$, Wulong and Lori Whewell, University Research and the Commercialization of Intellectual Property in Canada, Occasional Paper No. 21, Industry Canada Research Publications Program, Ottawa, April 1999.

Roy, Jeffrey, Year 1 Presentation, University of Waterloo, Economic Development Program, 2001.

Saint John. Imagine the Possibilities summary report, Enterprise Saint John, Saint John, 1999.

Saint John. Ready...Set...Grow, Enterprise Saint John, 2000.

Saint John. The Vision of Youth, Enterprise Saint John, Enterprise Saint John, 2000.

Sevier, Robert A., Integrated Marketing for Colleges, Universities, and Schools, Council for the Advancement and Support of Education, New York, 1998.

Smith, Larry and Emanuel Carvalho, The Greater Saint John Region: Opening Doors for the Future, Economic Essentials, Waterloo, 2000. 